\title{
Sri Lankan COVID-19 response: opinion from a senior public health specialist
}

\author{
Lakshman Abeyagunawardene \\ Public Health Specialist \\ Correspondence: adnl1102@gmail.com \\ DOI: https://doi.org/10.4038/jccpsl.v26i5.8344
}

Received on 25 May 2020

Accepted on 6 June 2020

Going through epidemics and outbreaks is not a novelty to Sri Lanka, which has been facing yearly outbreaks of dengue and leptospirosis for the past so many decades. When COVID-19 appeared however, it was not to be contended with implementation of the 'usual' measures conducted for outbreak control that Sri Lanka was 'familiar' with. Fortunately, those at the forefront of decision-making in the country and battling COVID-19 understood the need of changing tactics depending upon the dynamics of the disease from the initial stages.

Sri Lanka's COVID-19 response has been successful up to date and is driven onwards due to the strong political leadership and commendable administrative and technical backing. Since the very first case was reported in Sri Lanka on 27 January 2020, and thereafter when the first local citizen was reported, Sri Lanka too underwent difficult times in implementing robust prevention and control measures including enforcement of a modified-lockdown status, undertaking strong surveillance measures and indepth contact tracing and, of course, practicing the key WHO Guidelines. The healthcare workers, both in the fields as well as the hospitals rose admirably to the challenge. The professional associations, medical consultants, consultant community physicians and even trade unions like the GMOA played a remarkable role with timely technical advice being given to an equally receptive government. However, dark the clouds may seem, the silver lining now driving the impetus has been the absence of community spread of the disease as yet.

Much of the effort in containing COVID-19 has also been due to the admirable service rendered by the triforces and police. From the top level of a militarilytrained President and Task Force leaders, all the way down to the grass-root level military personnel engaged in contact tracing, these heroes have the grateful thanks of the entire country for their excellent performance in a completely different arena, using alien and hitherto unused 'battle' tactics. The utilization of Army Intelligence for epidemiological investigations as Sri Lanka has done may be a global first as well. The decision made by the political leadership in recruiting the help of trained military personnel other than the healthcare work force has proved to be a sound one.

The COVID-19 outbreak has been terrifying as well as it has been monumental in changing lives and reshaping the future of the country, possibly for better. Not only the healthcare system, but the entire country 
has been tried and tested and proved worthy of praise. The massive public support for the control programme and the practice of key public health practices such as hand washing and personal distancing have had positive results and the country is now geared to move to the 'next-level' with innovations being reported in manufacturing locally- made healthcare equipment and novel thinking taking root, in terms of home gardening and becoming self-sufficient. This level of empowerment is extraordinary and should be capitalized upon by the political leadership. Who knows, with the right backing, Sri Lanka may rise to these challenges as well as it has risen to overcome COVID-19. 